\title{
Thermodynamics-Aided Alloy Design and Evaluation of Pb-free Solders for High-Temperature Applications
}

\author{
Jong Hoon Kim, Sang Won Jeong and Hyuck Mo Lee* \\ Department of Materials Science and Engineering, Korea Advanced Institute of Science and Technology, \\ Kusung-Dong 373-1, Yusung-Gu Taejon 305-701, Korea
}

\begin{abstract}
High temperature solders that will not be affected in the subsequent thermal treatment are required in the step soldering process of multi-chip module (MCM) packaging. High- $\mathrm{Pb}$ solder alloys such as $95 \mathrm{~Pb}-5 \mathrm{Sn}$ (numbers are all in mass\% unless specified otherwise) are currently being used for this purpose. However, the development of the $\mathrm{Pb}$-free solder alloy for high temperature applications is needed due to environmental issues. The solder alloys of $\mathrm{Bi}-\mathrm{Ag}, \mathrm{Sn}-\mathrm{Sb}$ and $\mathrm{Au}-\mathrm{Sb}-\mathrm{Sn}$ systems are considered as candidates in this study. Aided by thermodynamic calculations, several specific compositions have been chosen and they were investigated in terms of melting behavior, electrical resistivity, wetting angle and hardness. The $\mathrm{Bi}-\mathrm{Ag}$ alloy exhibited poor electro-conductivity while the $\mathrm{Sn}-\mathrm{Sb}$ system had low melting temperatures. The ternary Au-Sn-Sb solder alloy shows prospects for high temperature applications in spite of poor wetting properties.
\end{abstract}

(Received March 15, 2002; Accepted May 21, 2002)

Keywords: alloy design, lead-free solder, high-temperature solder, step soldering, tin-antimony, bismuth-silver, gold-tin-antimony

\section{Introduction}

Advanced packaging technology is required because electronic devices are operating faster and becoming smaller, lighter and more functional. As a result, many advanced packaging technologies such as flip-chip technology, ball grid array (BGA), chip-scale package (CSP) and multi-chip module (MCM) have been developed. The MCM, one of the most advanced forms of electronic packaging, is a group of highly functional electronic devices interconnected to the substrate by fine-line circuitry, usually in the form of multilayers. The significant benefit of MCM is the increased system performance that results from the drastically shortened interconnection length between integrated circuit devices (chips). ${ }^{1)}$ When integrated circuit chips are packaged in MCM, step soldering is used. Step soldering is a method to solder various levels of the package with different solders of different melting points so that the soldering of each successive level or step does not melt the previously soldered joint inadvertently. ${ }^{2)}$ In general, the $95 \mathrm{~Pb}-5 \mathrm{Sn}$ solder with a melting temperature of $308-$ $312^{\circ} \mathrm{C}$ is used for high temperature applications in step soldering. However, due to environmental issues, the use of $\mathrm{Pb}$ is restricted and new $\mathrm{Pb}$-free high temperature solder alloys are required.

In designing new $\mathrm{Pb}$-free high temperature solder alloys, the melting behavior is important. In recent MCM packages, polymers are used as dielectric materials in the substrate, which implies that the glass transition temperature of the polymer, around $350^{\circ} \mathrm{C},{ }^{3)}$ may be the upper limit of temperature in soldering. The subsequent process temperature is the lower limit of melting points of solders so that the soldered joints should not melt in the subsequent process. Pb-free solder alloys that satisfy this melting characteristic are necessary. The mechanical and electrical properties of solders are important, too, because solder joints connect mechanically and electrically integrated circuit chips with the substrate.

In this study, the $\mathrm{Sn}-\mathrm{Sb}, \mathrm{Bi}-\mathrm{Ag}$ and $\mathrm{Au}-\mathrm{Sn}-\mathrm{Sb}$ alloys were selected to replace $95 \mathrm{~Pb}-5 \mathrm{Sn}$ for step soldering used in $\mathrm{MCM}$ and they were investigated in terms of melting behavior, electrical resistivity, wettability and hardness. Solder alloys with optimum properties will be determined in this way.

\section{Experimental Procedures}

All alloys were prepared from pure metals (purity higher than $99.9 \%$ ). Samples were encapsulated in quartz tubes under vacuum, melted and mechanically mixed. As-cast alloys were obtained by cooling in air. X-ray diffraction (XRD) measurements were performed to identify the phases formed in the solder alloys, and energy-dispersive X-ray (EDX) analyses were used to measure compositions. The microstructures were observed using scanning electron microscopy (SEM).

Vickers hardness tests were performed at a load of $300 \mathrm{~g}$ in order to examine the mechanical properties. The electrical resistivity was measured from thin foil samples. The 50 to $150 \mu \mathrm{m}$ thin foil samples were prepared by melting a small amount of solder placed between two sheets of plate glass in a nitrogen-purged oven at $350^{\circ} \mathrm{C}$. $^{4}$ ) The electrical resistivity was measured by four-point probe. To check the current method, pure Sn and Bi foils were prepared in the same way and their resistivity measured 11.77 and $107 \mu \Omega \cdot \mathrm{cm}$, respectively, which were in good agreement with published data of 11.5 and $107 \mu \Omega \cdot \mathrm{cm}^{5)}$ The wettability was measured by the wetting angle of solders on $\mathrm{Cu}$ and $\mathrm{Ni}$ substrates. Solder alloys $(0.3 \mathrm{~g}$ in mass $)$ were put on both substrates. The $0.5 \mathrm{~mm}$ thick substrate was polished with $1 \mu \mathrm{m}$ diamond paste and cleaned in aceton and ethanol solution. Soldering was performed in a convection reflow furnace longer than $60 \mathrm{~s}$. The peak temperature was $330^{\circ} \mathrm{C}$. The wetting angle was calculated from a cross section view of the joint specimen. ${ }^{6}$ ) 


\section{Results}

\subsection{Sn-Sb system}

The $\mathrm{Sn}-5 \mathrm{Sb}$ system is an alloy with a high melting point that has been developed to replace the widely used $\mathrm{Sn}-37 \mathrm{~Pb}$ solder. ${ }^{4)}$ According to the calculated phase diagram of $\mathrm{Sn}-$ $\mathrm{Sb}$ shown in Fig. $1,{ }^{7)}$ the melting temperature of $\mathrm{Sn}-5 \mathrm{Sb}$ is $240^{\circ} \mathrm{C}$ and it is slightly low for high temperature applications. Hence, an additional Sn-10Sb alloy with a higher amount of $\mathrm{Sb}$ was chosen as another candidate together with $\mathrm{Sn}-5 \mathrm{Sb}$.

Figure 2 shows SEM images by secondary electron (SE) mode of as-cast $\mathrm{Sn}-5 \mathrm{Sb}$ and $\mathrm{Sn}-10 \mathrm{Sb}$ alloys. While the $\beta$ Sn matrix was observed without a secondary phase in $\mathrm{Sn}-$ $5 \mathrm{Sb}$, the distribution of secondary particles was observed in $\mathrm{Sn}-10 \mathrm{Sb}$. Figure 3 shows XRD patterns of as-cast $\mathrm{Sn}-5 \mathrm{Sb}$ and $\mathrm{Sn}-10 \mathrm{Sb}$ alloys. Although the $\beta$-Sn matrix was observed alone without any secondary phase through SEM observation of $\mathrm{Sn}-5 \mathrm{Sb}$, the existence of the $\beta$-SbSn phase was detected together with $\beta$-Sn in both alloys. The secondary phase was identified as $\beta$-SbSn. The distribution of $\beta$-SbSn particles in the $\beta$-Sn matrix may result in improvement of mechanical properties and the Vickers hardness increased from 20.04 to $29.5 \mathrm{Hv}$ with an increased $\mathrm{Sb}$ content from 5 to 10 mass\%. Although the resistivity of $\mathrm{Sn}-\mathrm{Sb}$ increased with $\mathrm{Sb}$, it was similar to that of $95 \mathrm{~Pb}-5 \mathrm{Sn}$. It has been reported that the wettability of $\mathrm{Sn}-\mathrm{Sb}$ was improved with $\mathrm{Sb}^{8,9)}$ however, it decreased in this work. The basic properties of $\mathrm{Sn}-\mathrm{Sb}$ alloys and other solder candidates are listed in Table 1. The electrical resistivity of $\mathrm{Au}-20 \mathrm{Sn}$ is from Tummala et al. ${ }^{10)}$

\subsection{Bi-Ag system}

The melting point of $\mathrm{Bi}$ is $271^{\circ} \mathrm{C}$ and it satisfies the temperature requirement for step soldering while the resistivity of $\mathrm{Bi}$ is $107 \mu \Omega \cdot \mathrm{cm}$ and it is not suitable for high performance devices. As the conductivity of Ag is better, the addition of $\mathrm{Ag}$ to $\mathrm{Bi}$ is supposed to reduce resistivity. The calculated phase diagram of the binary $\mathrm{Bi}-\mathrm{Ag}$ system is shown in Fig. $4{ }^{11,12)}$ The $\mathrm{Bi}-2.5 \mathrm{Ag}$ alloy can be a good candidate because this composition is eutectic. The $\mathrm{Bi}-5 \mathrm{Ag}$ solder that contains more $\mathrm{Ag}$ was also selected to lower the resistivity.

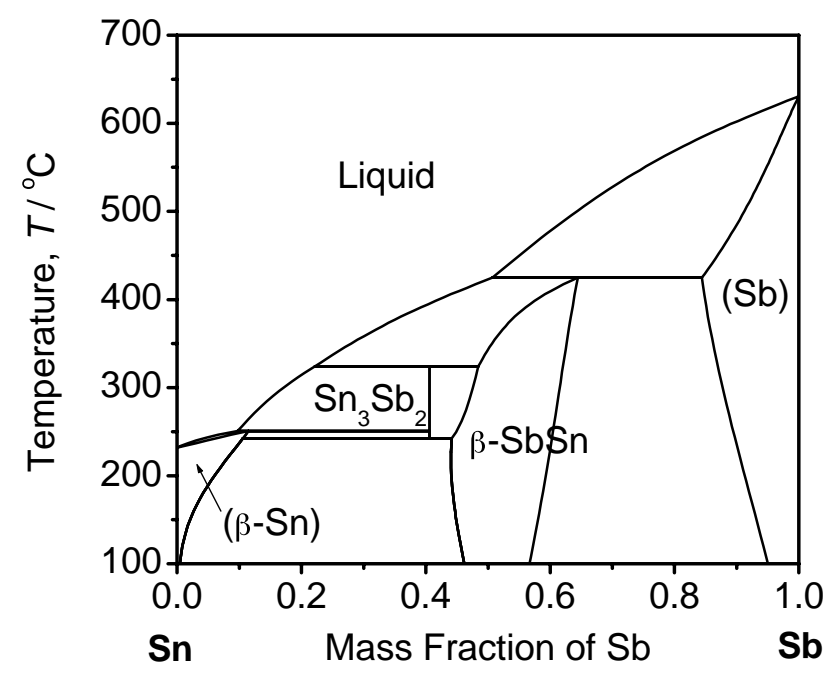

Fig. 1 Calculated phase diagram of the binary $\mathrm{Sn}-\mathrm{Sb}$ system. ${ }^{7)}$
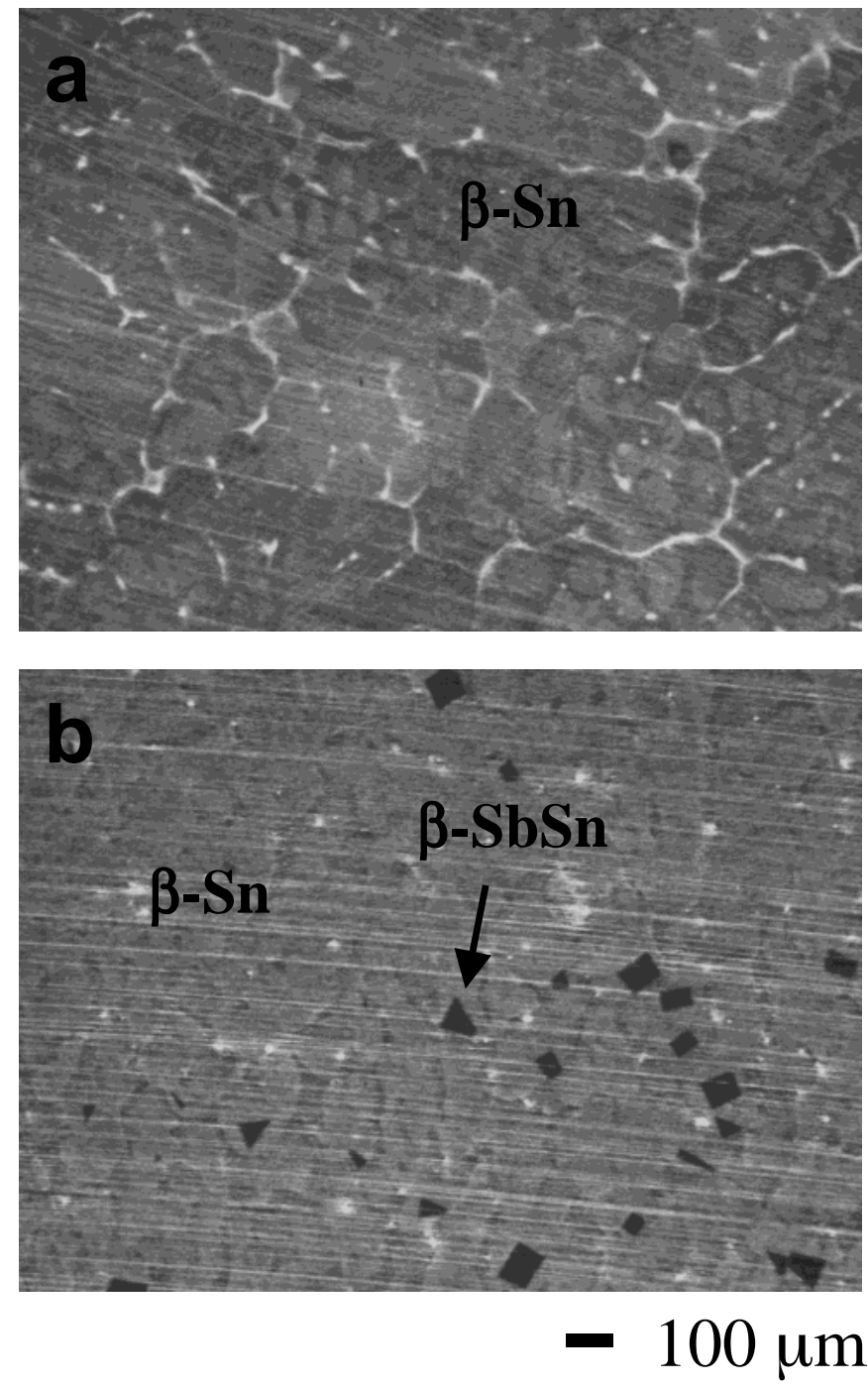

Fig. 2 SEM micrographs of as-cast (a) Sn-5Sb and (b) Sn-10Sb. SE mode used.

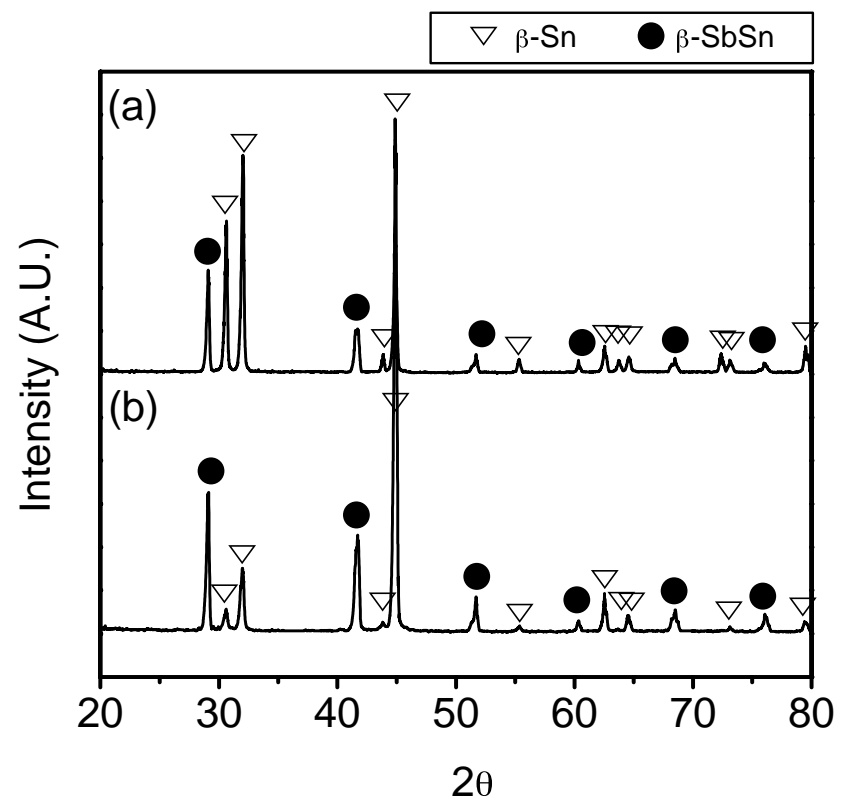

Fig. 3 XRD patterns of (a) $\mathrm{Sn}-5 \mathrm{Sb}$ and (b) $\mathrm{Sn}-10 \mathrm{Sb}$. 
Table 1 Properties of solder candidates compared with $\mathrm{Pb}-5 \mathrm{Sn}$ solder

\begin{tabular}{|c|c|c|c|c|}
\hline \multirow{2}{*}{ Solder (mass $\%$ ) } & \multirow{2}{*}{$\begin{array}{l}\text { Vickers hardness } \\
\text { (Hv) }\end{array}$} & \multirow{2}{*}{$\begin{array}{l}\text { Electrical resistivity } \\
\qquad(\mu \Omega \cdot \mathrm{cm})\end{array}$} & \multicolumn{2}{|c|}{ Wetting angle (degree) } \\
\hline & & & Cu substrate & Ni substrate \\
\hline $\mathrm{Pb}-5 \mathrm{Sn}$ & $8.9( \pm 0.17)$ & $17.47( \pm 0.66)$ & 21.37 & 20.21 \\
\hline $\mathrm{Sn}-5 \mathrm{Sb}$ & $20.0( \pm 0.97)$ & $15.87( \pm 2.20)$ & 13 & 14 \\
\hline $\mathrm{Sn}-10 \mathrm{Sb}$ & $29.5( \pm 3.13)$ & $22.00( \pm 0.53)$ & 46 & 28 \\
\hline $\mathrm{Bi}-2.5 \mathrm{Ag}$ & $15.0( \pm 0.99)$ & $110.30( \pm 0.83)$ & 79 & 91 \\
\hline $\mathrm{Bi}-5 \mathrm{Ag}$ & $15.2( \pm 2.5)$ & $123.60( \pm 8.43)$ & 62 & 118 \\
\hline $\mathrm{Au}-20 \mathrm{Sn}-5 \mathrm{Sb}$ & $200.2( \pm 9.11)$ & $33.29( \pm 1.10)$ & 55.85 & 69.39 \\
\hline
\end{tabular}

*Electrical resistivity of $\mathrm{Au}-20 \mathrm{Sn}$ is from Ref. 10).

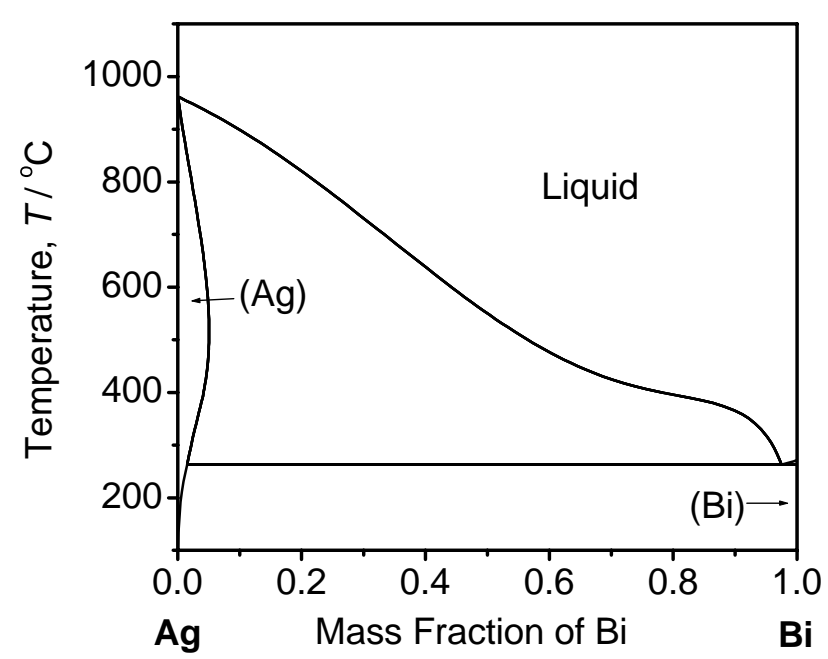

Fig. 4 Calculated phase diagram of the binary Ag-Bi system. ${ }^{11,12)}$

Figure 5 shows SEM images by back-scattered (BS) mode of as-cast eutectic $\mathrm{Bi}-2.5 \mathrm{Ag}$ and off-eutectic $\mathrm{Bi}-5 \mathrm{Ag}$. In Fig. 5(a), the distribution of $\mathrm{Ag}$ particles in the $\mathrm{Bi}$ matrix is observed clearly, and the primary Ag phase of the capital letter ' $H$ ' shape is observed in Fig. 5(b). The XRD patterns of $\mathrm{Bi}-2.5 \mathrm{Ag}$ and $\mathrm{Bi}-5 \mathrm{Ag}$ are shown in Fig. 6. The resistivity of the $\mathrm{Bi}-\mathrm{Ag}$ alloy was originally supposed to decrease with $\mathrm{Ag}$ content, however, the addition of $\mathrm{Ag}$ to $\mathrm{Bi}$ did not reduce the resistivity of the $\mathrm{Bi}-\mathrm{Ag}$ solder alloy probably due to the heterogeneous microstructure. This must have exerted a pronounced effect in impeding the electron motion, thereby increasing resistivity. ${ }^{13)}$ The $\mathrm{Bi}-\mathrm{Ag}$ alloys showed poor wettability on both $\mathrm{Cu}$ and $\mathrm{Ni}$ substrates. The hardness values of $\mathrm{Bi}-2.5 \mathrm{Ag}$ and $\mathrm{Bi}-5 \mathrm{Ag}$ alloys were similar to that of $\mathrm{Pb}-5 \mathrm{Sn}$, but the $\mathrm{Bi}-\mathrm{Ag}$ alloys showed weak and brittle behavior during handling of the specimen.

\subsection{Au-Sn-Sb system}

The Au-Sn solder has been used in the flip chip ${ }^{14)}$ because the melting point of $\mathrm{Au}-20 \mathrm{Sn}, 280^{\circ} \mathrm{C}$, satisfies the temperature requirement. Due to the high cost of $\mathrm{Au}$, the $\mathrm{Au}$ content needs to be reduced. It has been reported that alloying of $\mathrm{Sb}$ to $\mathrm{Au}-20 \mathrm{Sn}$ does not alter the melting temperature significantly. ${ }^{15)}$ In this regard, the Au-Sn-Sb system was chosen in this work and the phase diagram was calculated and shown in Fig. 7. ${ }^{16)}$ The differential scanning calorimeter (DSC) analysis was performed especially for $\mathrm{Au}-20 \mathrm{Sn}-5 \mathrm{Sb}$ to observe the
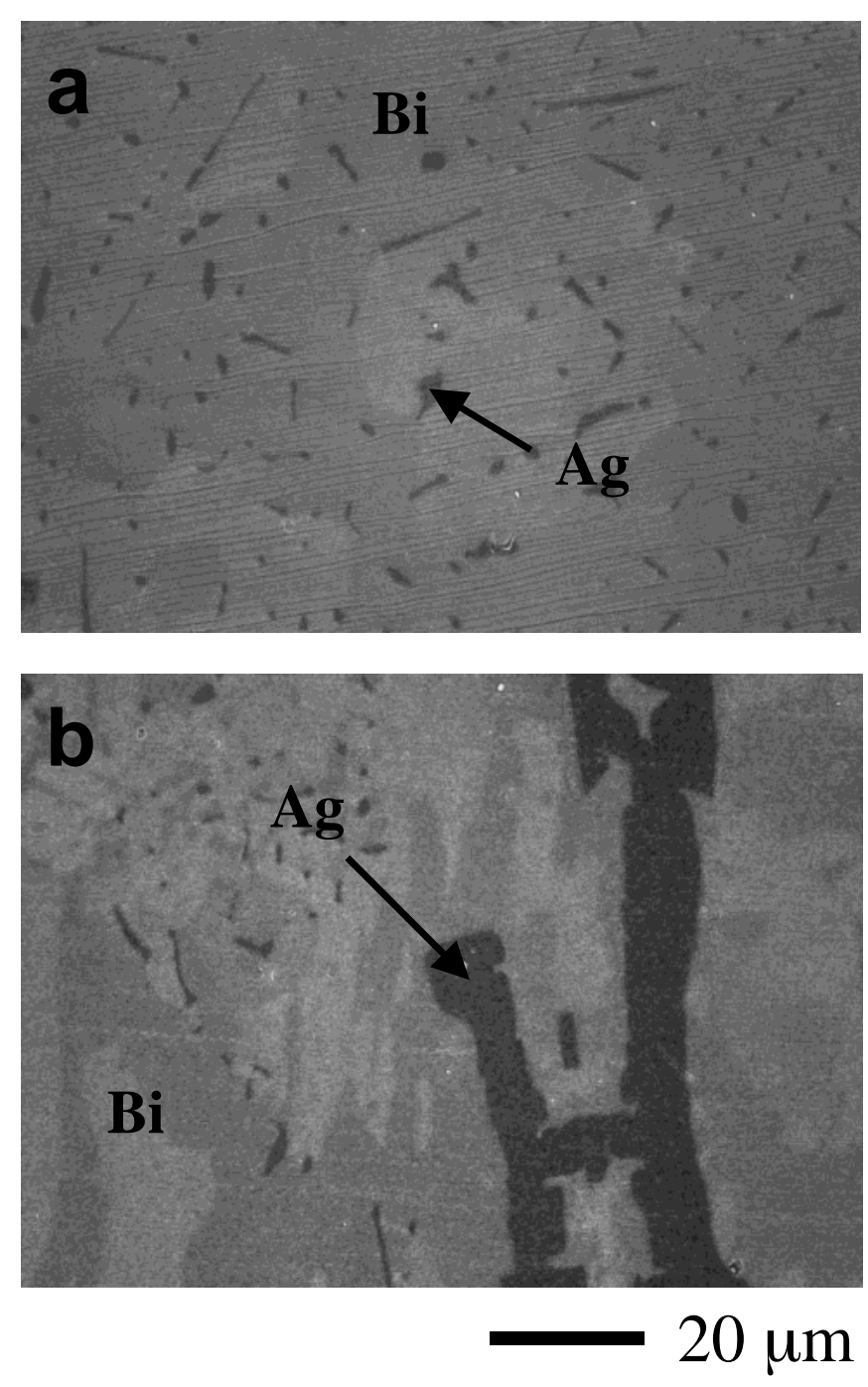

Fig. 5 SEM micrographs of as-cast (a) eutectic $\mathrm{Bi}-2.5 \mathrm{Ag}$ and (b) off-eutectic Bi-5Ag. BS mode used.

melting behavior. Both alloys of $\mathrm{Au}-20 \mathrm{Sn}$ and $\mathrm{Au}-20 \mathrm{Sn}-5 \mathrm{Sb}$ were tested here.

Figure 8 shows the BS-SEM images of the as-cast $\mathrm{Au}-$ $20 \mathrm{Sn}-5 \mathrm{Sb}$ alloy. The typical eutectic lamellar structure was observed in the matrix. The elongated gray particles were identified as AuSn. A line compound of the $\mathrm{Au}(\mathrm{Sb}, \mathrm{Sn})_{2}$ phase ${ }^{15,16)}$ exists according to phase equilibria, which implies that the $\mathrm{Sb}$ site in $\mathrm{Au}(\mathrm{Sb}, \mathrm{Sn})_{2}$ is substituted by $\mathrm{Sn}$ atoms. The blocky dark gray particles were determined as $\mathrm{AuSb}_{2}$ and 


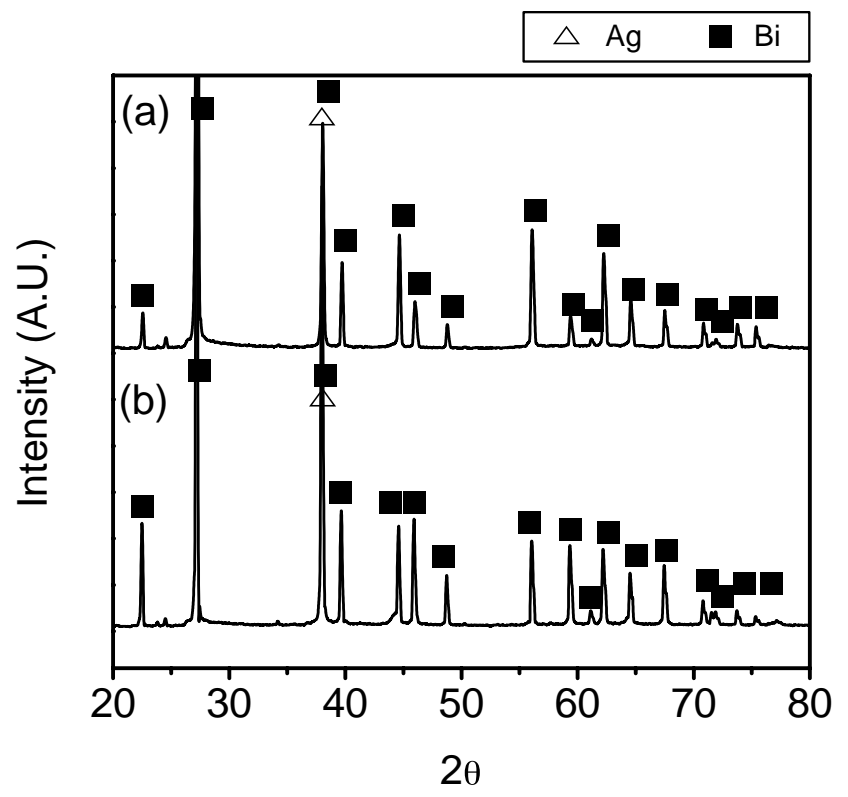

Fig. 6 XRD patterns of (a) $\mathrm{Bi}-2.5 \mathrm{Ag}$ and (b) $\mathrm{Bi}-5 \mathrm{Ag}$.

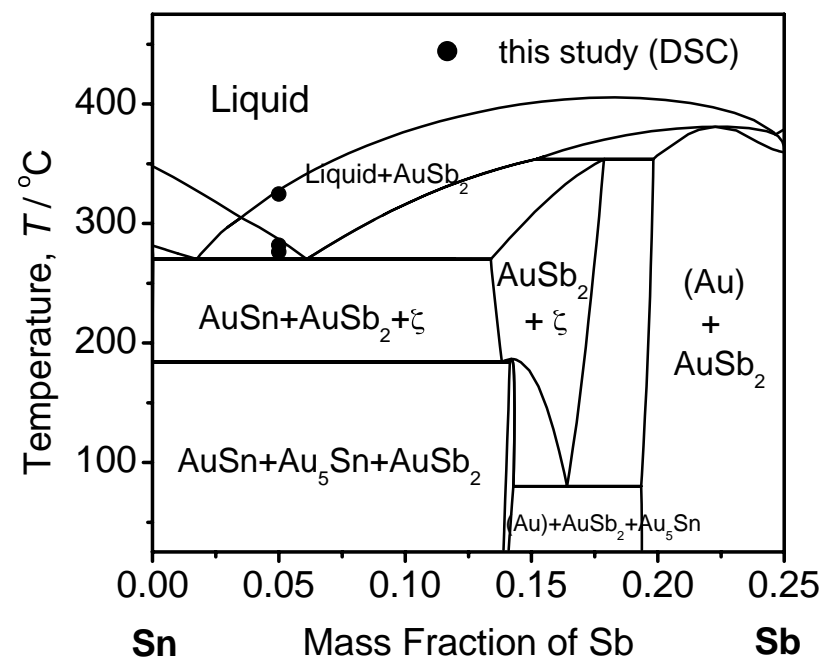

Fig. 7 Isoplethal phase diagram calculated along a constant amount of 75 mass\% Au in the ternary Au-Sb-Sn system. ${ }^{16)}$ Symbols represent DSC data in this study.

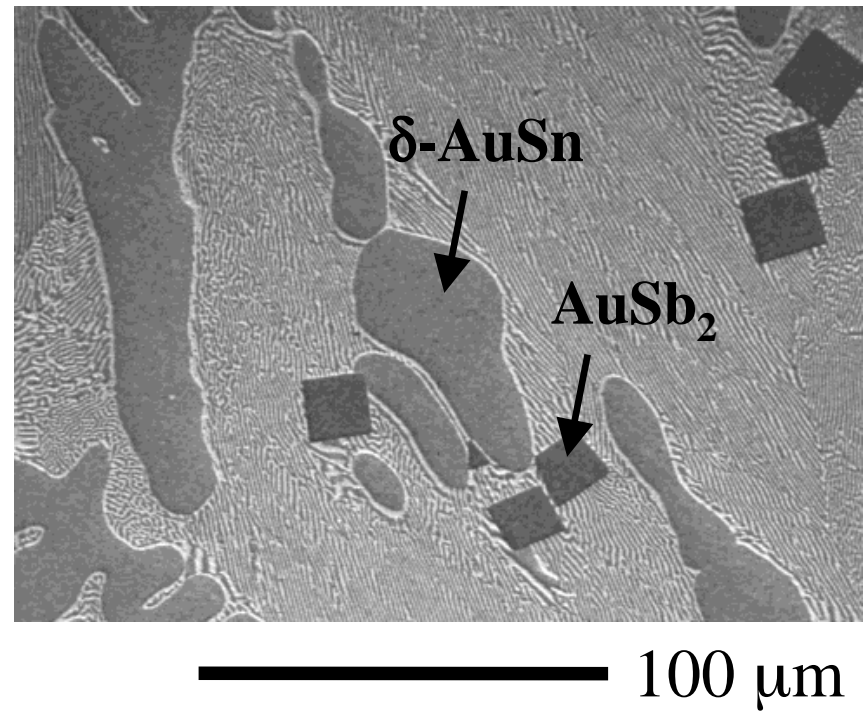

Fig. 8 SEM micrographs of as-cast Au-20Sn-5Sb. BS mode used.

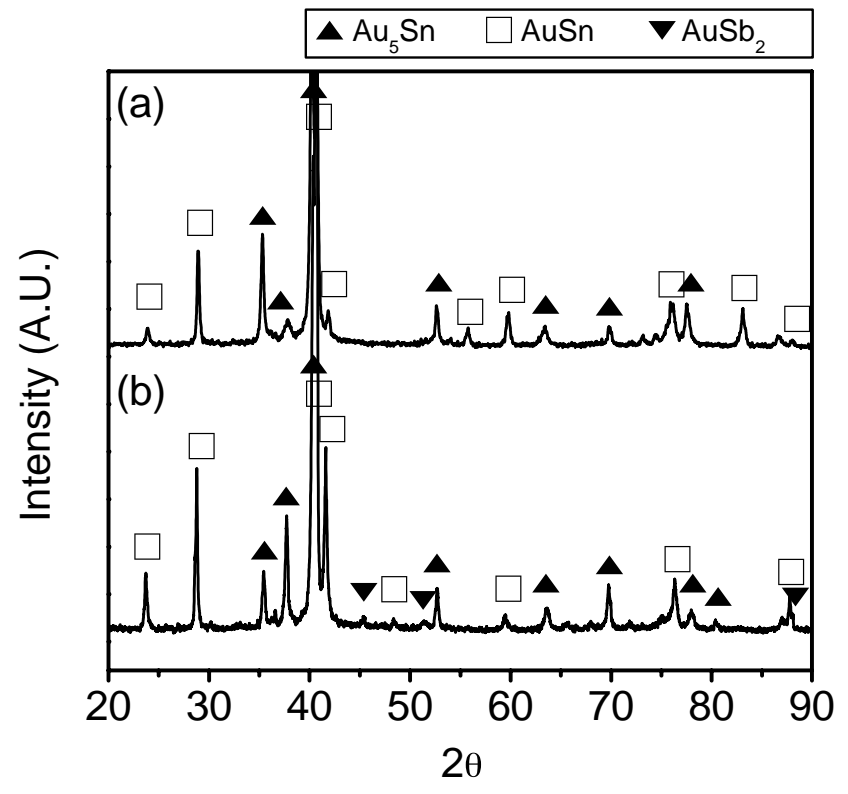

Fig. 9 XRD patterns of (a) Au-20Sn and (b) $\mathrm{Au}-20 \mathrm{Sn}-5 \mathrm{Sb}$.

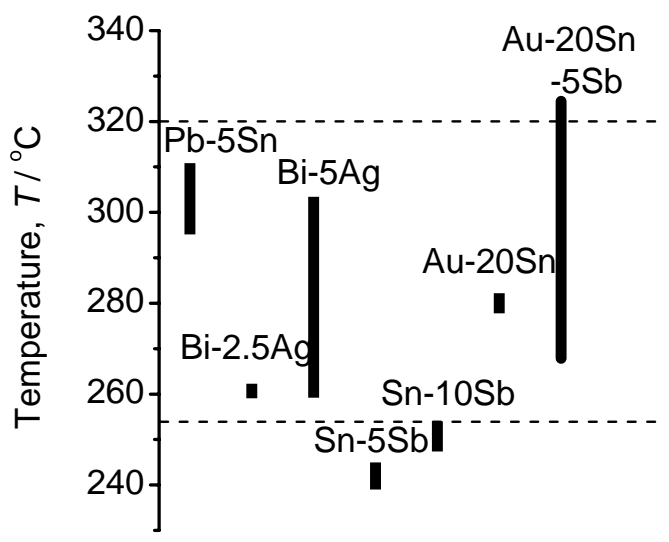

Fig. 10 Calculated melting temperatures of solders. The dotted line shows the melting range required for step soldering in $\mathrm{MCM}$ when the $\mathrm{Sn}-3.5 \mathrm{Ag}$ solder is used in the next level packaging.

the $\mathrm{Sn}$ content in this phase was measured at about 15 at $\%$. Figure 9 shows XRD patterns of $\mathrm{Au}-20 \mathrm{Sn}$ and $\mathrm{Au}-20 \mathrm{Sn}-$ $5 \mathrm{Sb}$. The Vickers hardness did not change much with an addition of $5 \mathrm{Sb}$. The resistivity and the wetting angle increased with alloying of $5 \mathrm{Sb}$.

\section{Discussion}

The calculated melting temperatures of selected solders and the required melting temperature range for step soldering are presented in Fig. 10. As the polymer with a glass transition temperature of around $350^{\circ} \mathrm{C}^{3)}$ is used as dielectric materials of substrate, the upper limit of the melting temperature of high temperature solders is $320^{\circ} \mathrm{C}$ in considering that the reflow temperature is about $30^{\circ} \mathrm{C}$ higher than the melting temperature of solders. If the $\mathrm{Sn}-37 \mathrm{~Pb}$ solder is used in the next level packaging, the lower melting temperature limit is $215^{\circ} \mathrm{C}$ which is $30^{\circ} \mathrm{C}$ higher than the melting temperature of $\mathrm{Sn}-37 \mathrm{~Pb}, 183^{\circ} \mathrm{C}$. When the $\mathrm{Sn}-3.5 \mathrm{Ag}$ solder is used for the next level, the lower melting temperature limit is $255^{\circ} \mathrm{C}$ because the melting point of $\mathrm{Sn}-3.5 \mathrm{Ag}$ is $221^{\circ} \mathrm{C}$. Assuming 


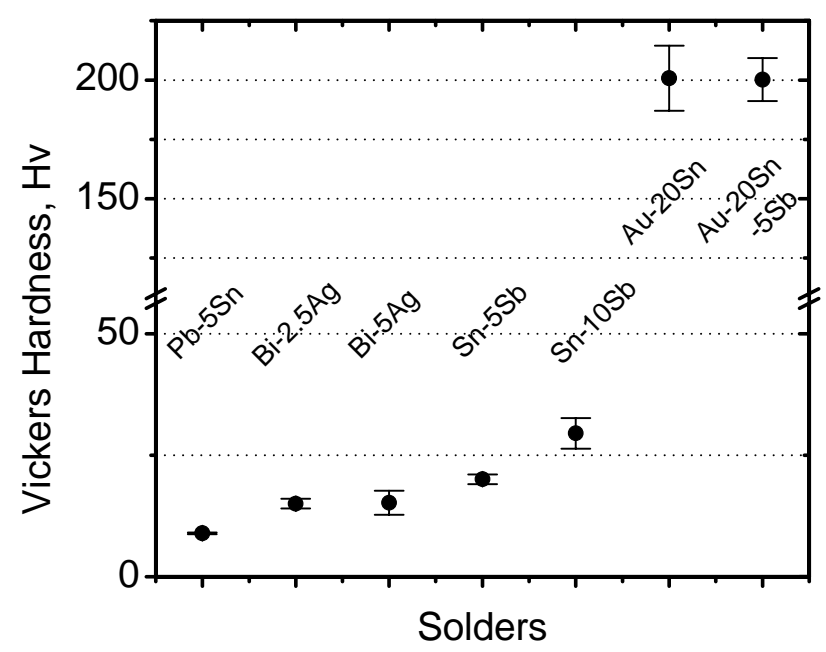

Fig. 11 Vickers hardness of solders.

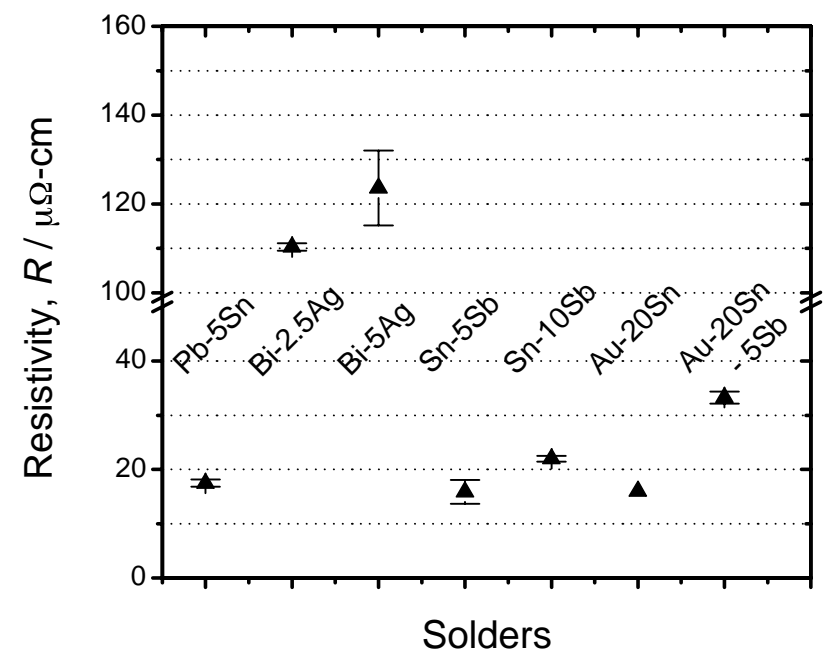

Fig. 12 Resistivity of solders. The data of Au-20Sn are from Ref. 10).

that the $\mathrm{Sn}-3.5 \mathrm{Ag}$ solder is used in the next level packaging, the required melting temperature for step soldering is between 255 to $320^{\circ} \mathrm{C}$. According to Fig. $10, \mathrm{Sn}-5 \mathrm{Sb}$ and $\mathrm{Sn}-10 \mathrm{Sb}$ are not suitable for high temperatures when $\mathrm{Sn}-3.5 \mathrm{Ag}$ is used in the subsequent packaging. Other solders are satisfactory in terms of the melting temperature. The liquidus temperature of $\mathrm{Au}-20 \mathrm{Sn}-5 \mathrm{Sb}$ is higher than $320^{\circ} \mathrm{C}$ and the melting range is so wide that modification of composition may be necessary.

Vickers hardness values of various solders are shown in Fig. 11. All of them are larger than that of $\mathrm{Pb}-5 \mathrm{Sn}, 8.9$ Hv. The hardness of $\mathrm{Au}-20 \mathrm{Sn}$ and $\mathrm{Au}-20 \mathrm{Sn}-5 \mathrm{Sb}$ is, especially, 20 times as large as that of $\mathrm{Pb}-5 \mathrm{Sn}$, and the addition of 5Sb did not change the hardness of Au-20Sn. Kloeser et $a l .{ }^{14)}$ tested the $\mathrm{Au}-20 \mathrm{Sn}$ bump electroplated on $\mathrm{Pd} / \mathrm{Ag}$ metallization and found that no electrical failures occurred in the chips with underfill after 6500 thermal cycles. The hard solders of Au-20Sn and Au-20Sn-5Sb appear to sustain high enough stress with proper underfill. Although the hardness of $\mathrm{Bi}-2.5 \mathrm{Ag}$ and $\mathrm{Bi}-5 \mathrm{Ag}$ is similar to that of $\mathrm{Pb}-5 \mathrm{Sn}$, the $\mathrm{Bi}-$ $\mathrm{Ag}$ alloy showed brittleness during experiments. This alloy looks unsuitable for solder alloy because of weak and brittle behavior.

The resistivitiy of solder candidates is shown in Fig. 12.

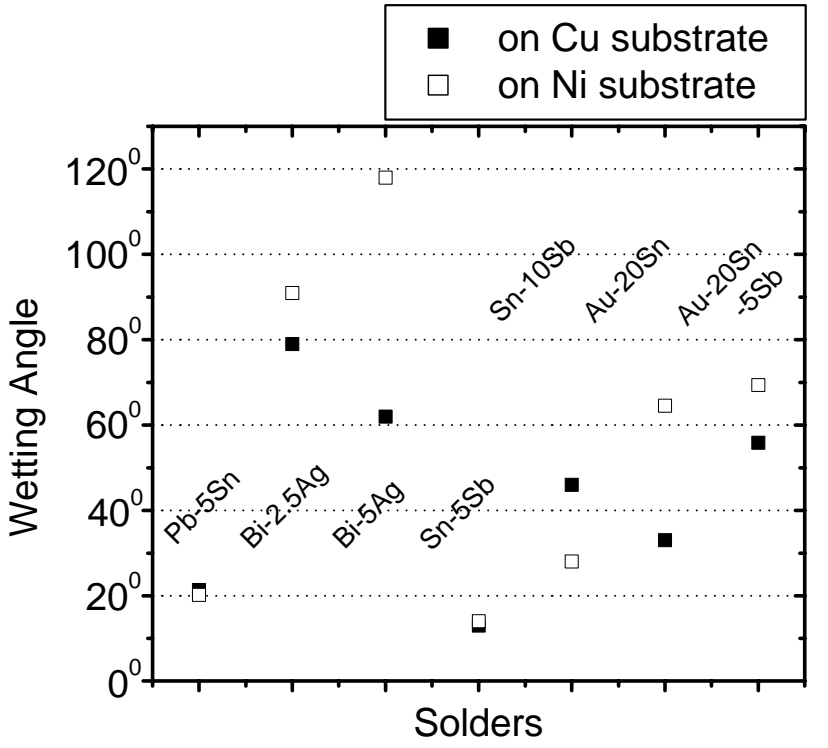

Fig. 13 Wetting angle of solder candidates measured on $\mathrm{Cu}$ and $\mathrm{Ni}$ substrates.

Except for $\mathrm{Bi}-2.5 \mathrm{Ag}$ and $\mathrm{Bi}-5 \mathrm{Ag}$, the resistivity is similar to that of $\mathrm{Pb}-5 \mathrm{Sn}$. The resistivity of $\mathrm{Bi}-2.5 \mathrm{Ag}$ and $\mathrm{Bi}-5 \mathrm{Ag}$ is so large that $\mathrm{Bi}-\mathrm{Ag}$ systems may be unsuitable for high performance devices. The wetting angles measured on $\mathrm{Cu}$ and $\mathrm{Ni}$ substrates are shown in Fig. 13. The $\mathrm{Bi}-2.5 \mathrm{Ag}$ and $\mathrm{Bi}-5 \mathrm{Ag}$ alloys showed poor wettability on both $\mathrm{Cu}$ and $\mathrm{Ni}$ substrates, and the $\mathrm{Sn}-5 \mathrm{Sb}$ and $\mathrm{Sn}-10 \mathrm{Sb}$ alloys exhibited good wettability that is compatible with that of $\mathrm{Pb}-5 \mathrm{Sn}$. It is, however, notable that the good wettability of $\mathrm{Sn}-\mathrm{Sb}$ alloys may have come from the high reflow temperature, $80^{\circ} \mathrm{C}$ higher than the melting temperature of Sn-Sb alloys. The $\mathrm{Au}-20 \mathrm{Sn}$ and $\mathrm{Au}-$ 20Sn-5Sb alloys showed high wetting angles, which necessitates the development of wettable layers such as $\mathrm{Pd} / \mathrm{Ag}^{14}$ ) for under bump metallurgy (UBM) of the $\mathrm{Au}-\mathrm{Sn}-\mathrm{Sb}$ solder system.

\section{Summary}

Three kinds of $\mathrm{Sn}-\mathrm{Sb}, \mathrm{Bi}-\mathrm{Ag}$ and $\mathrm{Au}-\mathrm{Sn}-\mathrm{Sb}$ alloys were selected to replace the $\mathrm{Pb}-5 \mathrm{Sn}$ solder for step soldering used in MCM and they were investigated in terms of melting behavior, electrical resistivity, wetting angle and hardness. The $\mathrm{Bi}-\mathrm{Ag}$ solders exhibited poor properties in all the tests. The $\mathrm{Sn}-\mathrm{Sb}$ solders showed desirable properties but it is likely that the next level packaging process may affect the $\mathrm{Sn}-\mathrm{Sb}$ solder. The $\mathrm{Au}-\mathrm{Sn}$ and $\mathrm{Au}-\mathrm{Sn}-\mathrm{Sb}$ solders showed a high potential as $\mathrm{Pb}$-free high temperature solders only with further modification of compositions for improvement of melting behavior and the development of UBM to enhance wetting.

\section{Acknowledgments}

This study has been supported by CEPM (Center for Electronic Packaging Materials) of the KOSEF (Korea Science and Engineering Foundation). 


\section{REFERENCES}

1) G. L. Ginsberg and D. P. Schnorr: Multichip Modules and Related Technologies, (McGraw-Hill, New York, 1994) pp. 19-22.

2) M. McCormack and S. Jin: JOM 45 (1993) 36-40.

3) G. L. Ginsberg and D. P. Schnorr: Multichip Modules and Related Technologies, (McGraw-Hill, New York, 1994) pp. 135-138.

4) S. K. Kang, J. Horkans, P. C. Andricacos, R. A. Carruthers, J. Cotte, M. Datta, P. Gruber, J. M. E. Harper, K. Kwietniak, C. Sambucetti, L. Shi, G. Brouillette and D. Danovitch: 49th Electronic Components and Technology Conference, (San Diego, 1999) 283-288.

5) CRC Handbook of Chemistry and Physics, 79th Ed., (CRC Press, Cleveland, 1998-1999) pp. 12-45.

6) Z. Mei and J. W. Morris, Jr.: J. Electron. Mater. 21 (1992) 599-607.

7) B. Jonsson and J. Agren: Mater. Sci. Techn. 2 (1986) 913-916.

8) J. W. Jang, P. G. Kim and K. N. Tu: J. Mater. Res. 14 (1999) 3895-3900.

9) B.-J. Lee and H. M. Lee: Design and Reliability of Solders and Solder
Interconnections, (TMS, Warrendale, 1997) pp. 129-136.

10) R. R. Tummala, E. J. Rymasezewski and A. G. Klopfenstein: Microelectronics Packaging Handbook, (Chapman and Hall, New York, 1997) pp. I-86.

11) B. Zimmermann: Ph. D. Thesis, (University of Stuttgart, Stuttgart, 1976).

12) U. R. Kattner and W. J. Boettinger: J. Electron. Mater. 23 (1994) $603-$ 610.

13) R. A. Flinn and P. K. Trojan: Engineering Materials and Their Applications, 4th ed., (John Wiley and Sons, New York, 1990) pp. S-113.

14) J. Kloeser, E. Zakel, F. Bechtold and H. Reichl: IEEE CPMT 19A (1996) 24-33.

15) A. Prince, G. V. Raynor and D. S. Evans: Phase Diagrams of Ternary Gold Alloys, (Institute of Metals, London, 1990) pp. 411-413.

16) J. H. Kim, S. W. Jeong and H. M. Lee: J. Electron. Mater. 31 (2002) 557-563. 